\title{
Lightness, chroma, and hue distributions in natural teeth measured by a spectrophotometer
}

\author{
Teuta Pustina-Krasniqi ${ }^{1}$, Kujtim Shala ${ }^{1}$, Gloria Staka ${ }^{1}$, Teuta Bicaj ${ }^{1}$, Enis Ahmedi ${ }^{1}$, \\ Linda Dula ${ }^{1}$
}

Correspondence: Dr. Teuta Pustina-Krasniqi

Email: teutapustina@hotmail.com
'Department of Prosthetic Dentistry, Dental Branch, Medical Faculty, University of Prishtina "Hasan Prishtina", Kosovo

\section{ABSTRACT}

Objective: The aim of the study was to analyze the distribution of color parameters, lightness $\left(\mathrm{L}^{*}\right)$, chroma $(\mathrm{C})$, hue $(\mathrm{H}), \mathrm{a}^{*}$ and $\mathrm{b}^{*}$, in the intercanine sector in maxilla. Material and Methods: Patients' tooth color measurements were performed using an intraoral spectrophotometer VITA Easyshade ${ }^{\circledR}$ (VITA Zahnfabrik H. Rauter GmbH and Co. KG, Bad Sackingen, Germany). The measurements were made in 255 subjects in the intercanine sector in maxilla. Results: The mean values for the group of 255 subjects were as follows: $\mathrm{L}^{*}, \mathrm{a}^{*}, \mathrm{~b}^{*}, \mathrm{C}$, and $\mathrm{H}$ as 81.6, 0.67, 21.6, 21.7, and 92.7, respectively. For $\mathrm{F}=206.27$ and $P<0.001$ between $\mathrm{L}^{*}, \mathrm{a}^{*}, \mathrm{~b}^{*}, \mathrm{C}, \mathrm{H}$, and central incisor/lateral incisor/canines, there were statistically significant differences. Conclusion: With the statistical analysis, it was determined that there are significant color differences between the teeth of the intercanine sector, which differences are clinically significant also.

Key words: Central incisors, lateral incisors, canines, spectrophotometer, teeth color

\section{INTRODUCTION}

The color and appearance of teeth are a phenomenon, created by a lot of factors such as lighting conditions, translucency, opacity, light scattering, gloss, and human perception. ${ }^{[1]}$ The color of teeth is strongly determined by dentin, with more translucent enamel who plays the lesser role through scattering at wavelengths in the blue range. ${ }^{[2]}$ The tubules are the predominant cause of light scattering in dentin, and in enamel, the hydroxyapatite crystals contribute significantly to scattering. ${ }^{[3]}$ Differences in tooth color exist among people, among the teeth in the same person and within the same tooth. When maxillary anterior were measured in vivo using a colorimeter, the general conclusion was that their color was not uniform. The other findings were as follows: (1) Base

\begin{tabular}{|l|l|}
\hline \multicolumn{3}{|c|}{ Access this article online } \\
\hline Quick Response Code: \\
\hline
\end{tabular}

of teeth color was presented by its middle third; (2) teeth in women were lighter, less chromatic, and less reddish-colored than men's; (3) aging produced darker and more reddish teeth; (4) cuspid teeth were darker than central incisors (CIs) or lateral incisors (LIs), and (5) CIs had the highest lightness. ${ }^{[4]}$ Karadas and Seven analyzed the changes of teeth color after bleaching. They concluded that after bleaching, patients should avoid drinks that cause tooth staining, particularly, red wine, tea, and cola. ${ }^{[5]}$ With the aim to maximize shade matching results, a thorough understanding of appearance attributes of natural teeth is required along with new shade guides and shade taking instruments. ${ }^{[6]}$ The majority of the studies of the teeth color determinations with digital devices

This is an open access article distributed under the terms of the Creative Commons Attribution-NonCommercial-ShareAlike 3.0 License, which allows others to remix, tweak, and build upon the work non-commercially, as long as the author is credited and the new creations are licensed under the identical terms.

For reprints contact: reprints@medknow.com

How to cite this article: Pustina-Krasniqi T, Shala K, Staka G, Bicaj T, Ahmedi E, Dula L. Lightness, chroma, and hue distributions in natural teeth measured by a spectrophotometer. Eur J Dent 2017;11:36-40.

DOI: $10.4103 / 1305-7456.202635$ 
were based on color parameters established in 1976 by the Commission Internationale de l'Eclairage (CIE). ${ }^{[7]}$ In literature, color is described based on the Munsell color space in terms of lightness, chroma, and hue. ${ }^{[8]}$ The CIE L*a*b* color space has a vertical axis that indicates relative lightness or darkness. The two horizontal axes represent the amounts of $a^{*} \sim$ red/ green and $b^{*} \sim$ yellow/blue. In the $L^{*} a^{*} b^{*}$ color space, it is described as: Lightness $\left(\mathrm{L}^{*}\right)$ is a measure of the lightness of an object, which represents the quantity of light reflected by an object, ${ }^{[9]}$ parameter $a^{*}$ is a measure of redness $/ a>0 /$ or greenness $/ a<0 /$, and parameter $b^{*}$ is a measure of yellowness $/ b>0$ / or blueness $/ b<0 /$. Chroma (C) (saturation) is the strength or dominance of the hue. Otherwise, it can be described as a saturation of a color. Hue $(\mathrm{H})$ describes a dimension of color. Based on Munsell hue, lightness, and chroma, the VITA company constructed the three-dimensional master for visual determination of the teeth color. This guide consists of lightness $(1,2,3,4$, and 5$)$, hue (L, M, or R), and chroma $(1,1.5,2,2.5$, or 3$) .{ }^{[10]}$ The lightness should be determined first, than chroma and then hue. ${ }^{[11]}$ Based on Hammad, the visual determination of shade is unreliable and inconsistent. ${ }^{[8]}$ Currently, there are a number of commercial systems such as colorimeters, spectrophotometers, digital color analyzers, and hybrid instruments that combine these technologies. ${ }^{[10]}$ The devices for shade selection are spectrophotometers, colorimeters, digital cameras, and red, green, blue devices. Choi et al. concluded that digital analysis of the teeth color is more accurate and reproducible than a visual assessment. ${ }^{[12]}$ There are disadvantages of using a colorimeter for measuring tooth. The instrument is designed to measure flat surfaces, and as a result to this, there are significant edge-loss effects. ${ }^{[13,14]}$ VITA Easyshade is a handheld spectrophotometer for tooth shade matching. ${ }^{[10]}$ It makes possible the color determination for natural and bleached teeth and a variety of restorations. It has the capability to measure the color in the vestibular thirds including cervical, middle, and incisal area. ${ }^{[15]}$ Based on Paul et al., the spectrophotometric shade analysis and communication can be used efficiently for porcelain-fused-to-metal restorations. ${ }^{[16]}$

\section{MATERIALS AND METHODS}

The measurements were made in 255 patients in the intercanine sector in maxilla. Digital recording was made in the middle third of the vestibular surface of the nonrestored and nondiscolored teeth in the intercanine sector. In this study, for digital tooth shade determination, it was used the spectrophotometer VITA Easyshade $^{\circledR}$ (VITA Zahnfabrik H Rauter GmbH and Co. KG, Bad Sackingen, Germany) [Figure 1].

The shade matching device was operated according to the manufacturer's instructions. The infection control shields were used [Figures 2 and 3]. The probe tip of the spectrophotometer stayed at $90^{\circ}$ to the surface of the tooth.

The statistical analyses were performed with Statistical program: Statistica 7.1 (StatSoft,Inc.2300 East 14 ${ }^{\text {th }}$ Street Tulsa, OK 74104, USA). The differences of the analyzed parameters in relation $\mathrm{CI} / \mathrm{LI} / \mathrm{C}$ were tested with ANOVA/MANOVA/(p). The study results were presented in graphicons and tables.

\section{RESULTS (ANOVA/MANOVA/CENTRAL INCISORS/LATERAL INCISORS/CANINES)}

In graficons, 1, 2, 3, 4, and 5 presented the distributions of lightness $\left(L^{*}\right)$, chrome $(C)$, hue $(H), a^{*}$, and $b^{*}$ for CI/LI/C. For Analysis of Variance (F); F=206.27 and $P<0.001(P=0,000)$, there were statistically significant differences between central incisors, lateral incisors and canines. The descriptive statistics of the lightness $\left(\mathrm{L}^{*}\right)$ in CIs, LIs, canines $(\mathrm{C})$ was shown in Table 1 . The mean value for parameter $L^{*}$ in total was 81.6. The highest value was registered in CIs 82.6, than in LIs 82.3, whereas canines had the lowest lightness 79.9. The chrome as the parameter of the saturation of the teeth color in total was 21.7. In canines, the chrome was 26.7, whereas in LIs, 19.5, and in CIs, 18.8 [Table 2]. Table 3 presents the descriptive statistics of hue, which in total was 92.7.

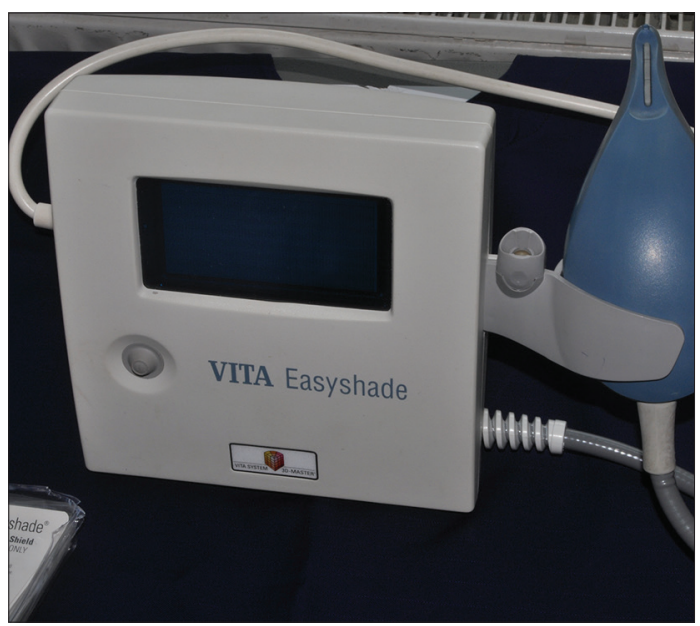

Figure 1: The spectrophotometer VITA Easyshade 


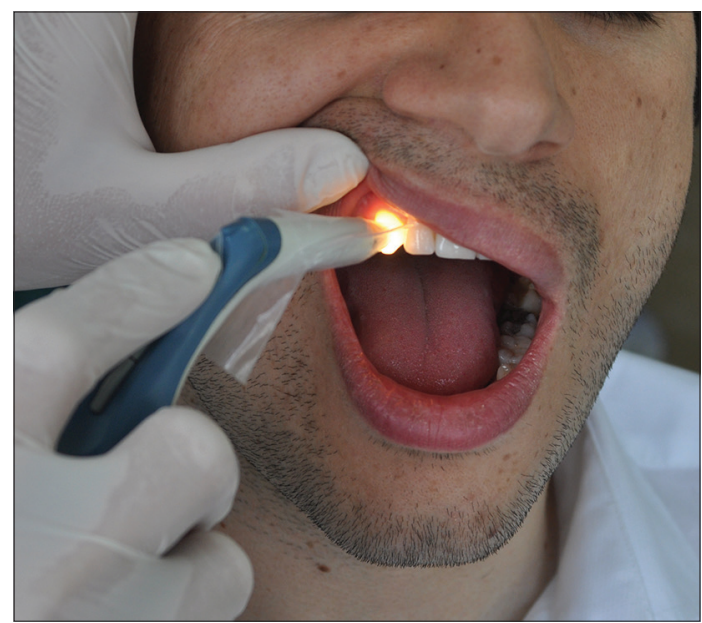

Figure 2: The infection control shields for the tip of the probe were used

\begin{tabular}{|c|c|c|c|c|c|c|c|}
\hline & \multirow{2}{*}{$\begin{array}{l}\text { Level } \\
\text { of } \\
\text { factor }\end{array}$} & \multicolumn{6}{|c|}{$L^{*}$} \\
\hline & & $n$ & Mean & SD & SE & $-95.00 \%$ & $+95.00 \%$ \\
\hline Total & & 2295 & 81.66 & 6.19 & 0.12 & 81.41 & 81.92 \\
\hline \multirow[t]{3}{*}{ Tooth } & $\mathrm{Cl}$ & 765 & 82.69 & 6.79 & 0.24 & 82.21 & 83.18 \\
\hline & $\mathrm{LI}$ & 765 & 82.31 & 6.03 & 0.21 & 81.88 & 82.74 \\
\hline & $C$ & 765 & 79.99 & 5.30 & 0.19 & 79.61 & 80.36 \\
\hline
\end{tabular}

Cl: Central incisor, LI: Lateral incisor, C: Canine, SD: Standard deviation, SE: Standard error

\begin{tabular}{lccccccc}
\multicolumn{3}{c}{$\begin{array}{c}\text { Table 2: Descriptive statistics for chrome (C) } \\
\text { factor }\end{array}$} & $\boldsymbol{n}$ & \multicolumn{4}{c}{ Chrome (C) } \\
\cline { 3 - 7 } & & Mean & SD & SE & $\mathbf{- 9 5 . 0 0 \%}$ & $\mathbf{+ 9 5 . 0 0 \%}$ \\
\hline Total & & 2295 & 21.70 & 5.59 & 0.11 & 21.47 & 21.93 \\
Teeth & Cl & 765 & 18.83 & 4.18 & 0.15 & 18.54 & 19.13 \\
& LI & 765 & 19.58 & 4.14 & 0.15 & 19.28 & 19.87 \\
& C & 765 & 26.70 & 4.64 & 0.16 & 26.37 & 27.02 \\
\hline
\end{tabular}

Cl: Central incisor, LI: Lateral incisor, C: Canine, SD: Standard deviation, SE: Standard error

\begin{tabular}{|c|c|c|c|c|c|c|c|}
\hline & \multirow{2}{*}{$\begin{array}{l}\text { Level of } \\
\text { factor }\end{array}$} & \multirow[t]{2}{*}{$n$} & \multicolumn{5}{|c|}{ Hue $(\mathrm{H})$} \\
\hline & & & Mean & SD & SE & $-95.00 \%$ & $+95.00 \%$ \\
\hline Total & & 2295 & 92.74 & 4.53 & 0.09 & 92.55 & 92.93 \\
\hline \multirow[t]{3}{*}{ Tooth } & $\mathrm{Cl}$ & 765 & 95.19 & 4.11 & 0.14 & 94.90 & 95.49 \\
\hline & $\mathrm{LI}$ & 765 & 93.61 & 3.97 & 0.14 & 93.33 & 93.89 \\
\hline & $\mathrm{C}$ & 765 & 89.42 & 3.32 & 0.12 & 89.18 & 89.65 \\
\hline
\end{tabular}

Cl: Central incisor, LI: Lateral incisor, C: Canine, SD: Standard deviation, SE: Standard error

The highest value of Hue was registered in CIs 95.1, in LIs 93.6, and in canines 89.4. In Table 4, the mean value for parameter $\mathrm{a}^{*}$ (red-green) was -0.67 ; for CIs was -1.50 ; for LIs was -1.0 ; and for canines was 0.48 . The mean value for parameter $b^{*}$ (yellow-blue) was 21.6. The highest value was in canines, 26.6 [Table 5].

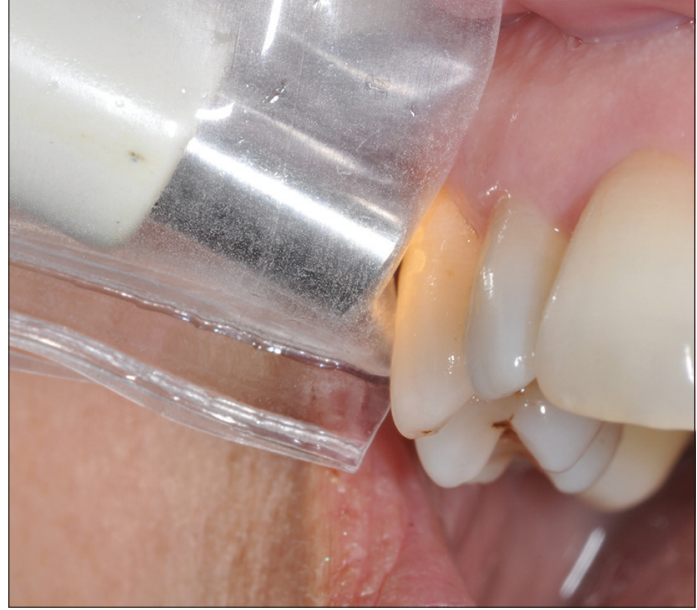

Figure 3: Tip of the probe with infection control shield

\section{DISCUSSION}

Based on results of this study, the mean value for parameter $\mathrm{L}^{*}, \mathrm{a}^{*}$, and $\mathrm{b}^{*}$ in total was $81.6,-0.67$, and 21.6 , respectively. The lowest value for the lightness was registered in canines 79.9, which showed that this group of teeth has less lightness than CIs and LIs. Having in mind that parameter $\mathrm{a}^{*}$ is a measure of redness $/ a>0 /$ and greenness $/ a<0 /$, in this study, the mean value for parameter $a^{*}$ was -0.67 ; we can identify that teeth of the intercanine sector contains more green pigment than red. The results showed that $\mathrm{a}^{*}$ for CIs was -1.50 , for LIs was -1.0 and for canines was 0.48 . The mean value for parameter $b^{*}$ (yellow-blue) was 21.6. The highest value was in canines 26.6. This fact once again proves the yellowness of the canines, which is also clinically evident. In addition, in canines, the chrome was 26.7, higher than in LIs 19.5 and in CIs 18.8. Based on $\mathrm{O}^{\prime}$ Brien et al., the results were as follows: $72.6+5.5,1.5+1.4,18.4 \pm 4.4$ for the gingival region, $72.4 \pm 5.1,1.2 \pm 1.0,16.2 \pm 4.6$ for the middle region, and $71.4 \pm 5.0,0.9 \pm 1.2,12.8 \pm 3.8$ for the incisal region. ${ }^{[17]}$ The descriptive statistics of hue, in total was 92.7. The highest value of hue was registered in CIs 95.1, in LIs 93.6, and in canines 89.4. The color of the restorations is a significant factor affecting dental appearance of maxillary anterior teeth in patients, and therefore, the clinician has to be very careful in choosing the right one using reliable tools. ${ }^{[18]}$ Sykora concluded that the determination of the color of posterior teeth should be based on premolars and for

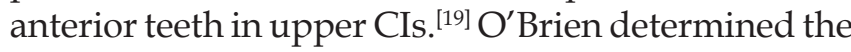
color of the twenty shades in the Ivoclar Chromascop shade guide and compared with the colors of 335 human teeth. The investigation with Chromascop guide showed results for $L^{* 79.67-65.61, ~} \mathrm{a}^{*}-0.71-3.85$, 
Pustina-Krasniqi, et al.: Teeth color parameters measured by a spectrophotometer

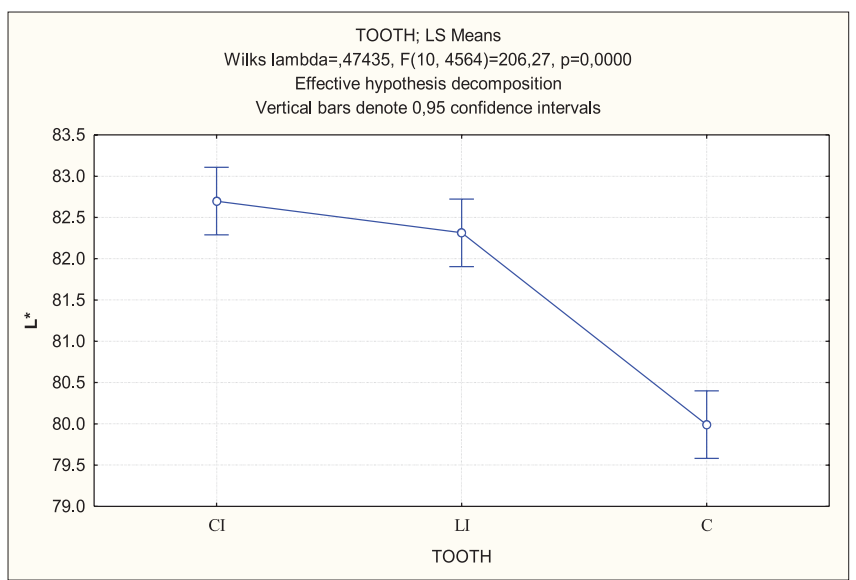

Graficon 1: Lightness in CI/LI/C. CI: Central incisor, LI: Lateral incisor, C: Canine, $P<0.001$

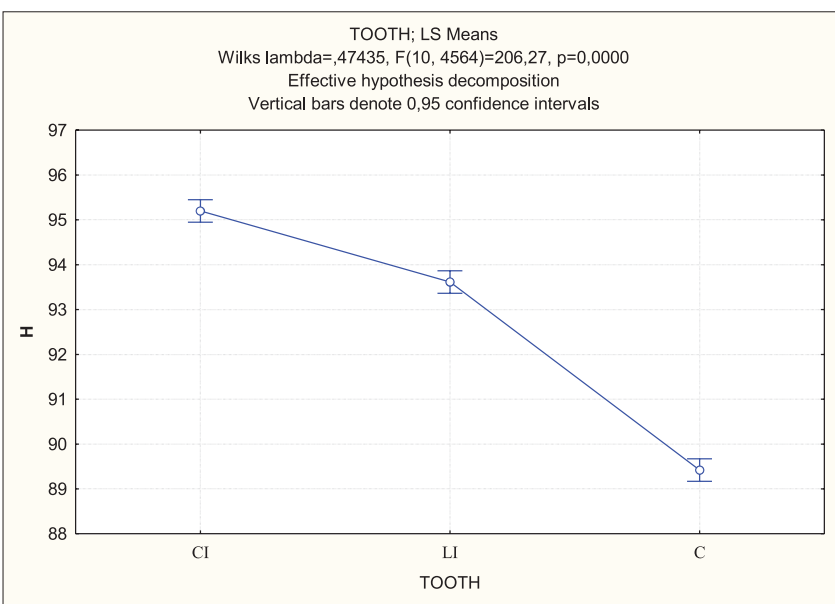

Graficon 3: Hue in CI/LI/C. CI: Central incisor, LI: Lateral incisor, C: Canine, $P<0.001$

\begin{tabular}{|c|c|c|c|c|c|c|c|}
\hline & \multirow{2}{*}{$\begin{array}{l}\text { Level of } \\
\text { factor }\end{array}$} & \multirow[t]{2}{*}{$n$} & \multicolumn{5}{|c|}{$a^{*}$} \\
\hline & & & Mean & SD & SE & $-95.00 \%$ & $+95.00 \%$ \\
\hline Total & & 2295 & -0.67 & 1.41 & 0.02 & -0.73 & -0.61 \\
\hline \multirow[t]{3}{*}{ Tooth } & $\mathrm{Cl}$ & 765 & -1.50 & 0.98 & 0.03 & -1.57 & -1.43 \\
\hline & LI & 765 & -1.00 & 1.13 & 0.04 & -1.08 & -0.92 \\
\hline & $C$ & 765 & 0.48 & 1.26 & 0.04 & 0.39 & 0.57 \\
\hline
\end{tabular}

Cl: Central incisor, LI: Lateral incisor, C: Canine, SD: Standard deviation, SE: Standard error

\begin{tabular}{lccccccc}
\multicolumn{2}{l}{ Table 5: Descriptive statistics for b* } \\
\hline \multirow{2}{*}{$\begin{array}{c}\text { Level of } \\
\text { factor }\end{array}$} & $\boldsymbol{n}$ & \multicolumn{5}{c}{$\mathbf{b}^{*}$} \\
\cline { 3 - 8 } & & Mean & SD & SE & $-95.00 \%$ & $\mathbf{+ 9 5 . 0 0 \%}$ \\
\hline Total & & 2295 & 21.64 & 5.63 & 0.11 & 21.41 & 21.87 \\
Tooth & Cl & 765 & 18.75 & 4.25 & 0.15 & 18.45 & 19.05 \\
& LI & 765 & 19.51 & 4.18 & 0.15 & 19.21 & 19.81 \\
& C & 765 & 26.67 & 4.65 & 0.16 & 26.34 & 27.00
\end{tabular}

Cl: Central incisor, LI: Lateral incisor, C: Canine, SD: Standard deviation, SE: Standard error

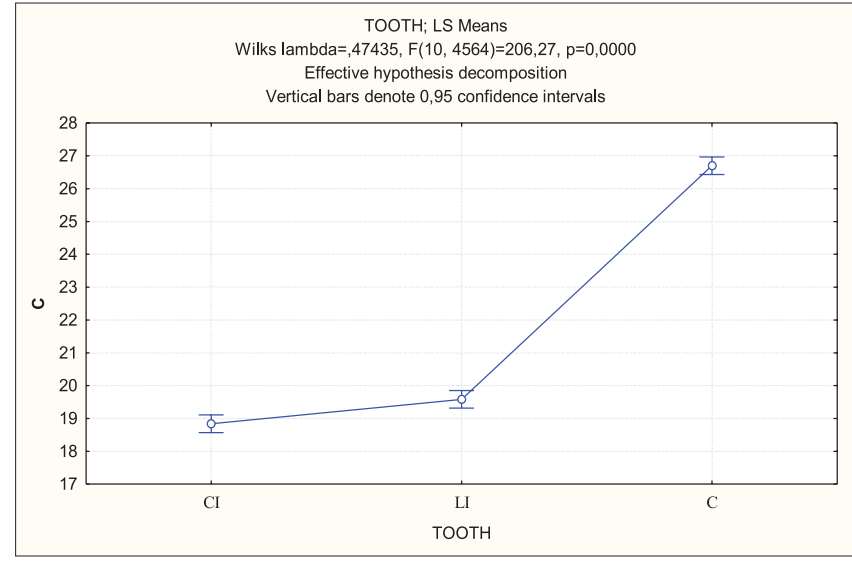

Graficon 2: Chrome in CI/LI/C. CI: Central incisor, LI: Lateral incisor, C: Canine, $P<0.001$

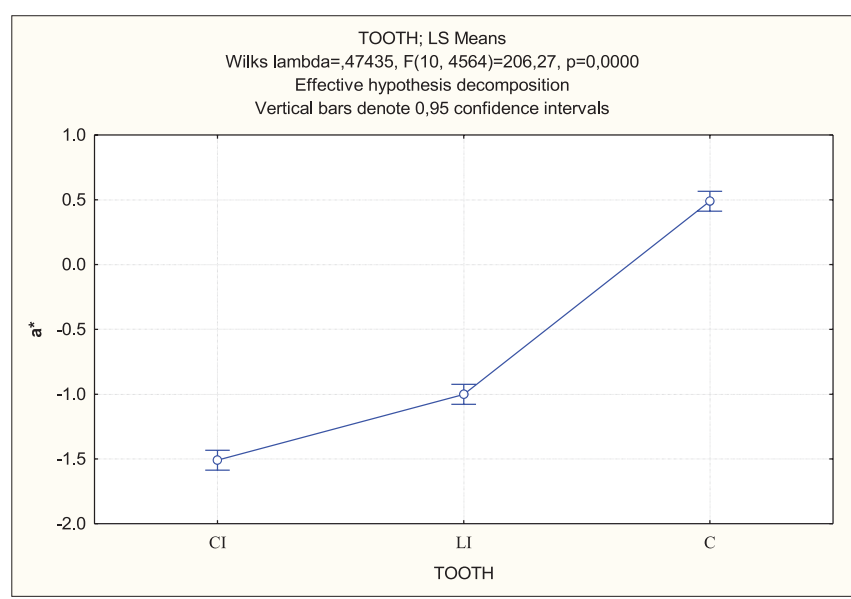

Graficon 4: Parameter a* in CI/LI/C. CI: Central incisor, LI: Lateral incisor, $\mathrm{C}$ : Canine, $P<0.001$

and $b^{*} 14.58-27.69 .{ }^{[20]}$ In our study were compared the natural teeth color of the intercanine sector and the minimum and maximum results for $L^{*}, a^{*}, b^{*}$ ranged: 81.41 to $81.92 ;-0.73$ to -0.61 and 21.41 to 21.87 . The digital devices for teeth color determination are attractive because it allows an objective assessment of the color. ${ }^{[21-23]}$ Elamin et al. during identifying the tooth shade using VITA Easyshade concluded that most frequent shade was A3 and women's teeth were lighter than men's. There was a relation between ethnic background and tooth shade. ${ }^{[24]}$

\section{CONCLUSION}

Because of their esthetic importance, the intercanine sector in maxilla was used. The parameter $L^{*}$ in CIs was higher than in LIs, whereas in canines, these values were much lower. The parameter $\mathrm{C}$ was much higher in canines than in incisors. The greenness was more 


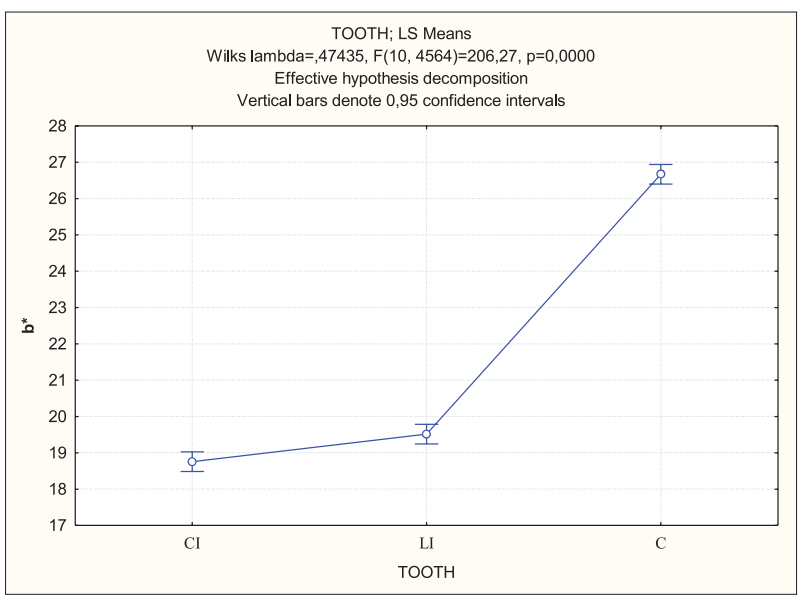

Graficon 5: Parameter b* in CI/LI/C. CI: Central incisor, LI: Lateral incisor, C: Canine, $P<0.001$

evident in incisors and redness in canines. Due to the fact that natural teeth colors are polychromatic, the written prescriptions are the most effective methods for sending detailed information to the dental laboratory.

\section{Acknowledgments}

We acknowledge all the subjects from the University Dentistry Clinical Center, Prishtina, Kosovo, who were volunteers for teeth color determination by a spectrophotometer and facilitated in this study.

\section{Financial support and sponsorship}

Nil.

\section{Conflicts of interest}

There are no conflicts of interest.

\section{REFERENCES}

1. Joiner A. Tooth colour: A review of the literature. J Dent 2004;32 Suppl 1:3-12.

2. ten Bosch JJ, Coops JC. Tooth color and reflectance as related to light scattering and enamel hardness. J Dent Res 1995;74:374-80.

3. Vaarkamp J, ten Bosch JJ, Verdonschot EH. Propagation of light through human dental enamel and dentine. Caries Res 1995;29:8-13.

4. Goodkind RJ, Schwabacher WB. Use of a fiber-optic colorimeter for in vivo color measurements of 2830 anterior teeth. J Prosthet Dent 1987;58:535-42.

5. Karadas M, Seven N. The effect of different drinks on tooth color after home bleaching. Eur J Dent 2014;8:249-53.

6. Cho BH, Lim YK, Lee YK. Comparison of the color of natural teeth measured by a colorimeter and shade vision system. Dent Mater 2007;23:1307-12.

7. $\mathrm{CIE}($ Commission Internationale del'Eclairage). Colorimetry-Technical Report. CIE Pub. No. 15. $3^{\text {rd }}$ ed. Vienna: Bureau Central de la CIE; 2004.

8. Hammad IA. Intrarater repeatability of shade selections with two shade guides. J Prosthet Dent 2003;89:50-3.

9. Ahmad I. Colour and shade analysis. Protocols for Predictable Aesthetic Dental Restorations. Ch. 4. Oxford: Blackwell Munksgaard; 2006. p. 77-97.

10. Paravina RD, Powers JM. Esthetic Color Training in Dentistry. St. Louis: Mosby; 2004.

11. Powers JM, Sakaguchi RL. Craig's Restorative Dental Materials. $12^{\text {th }}$ ed. St. Louis: Elsevier; 2006. p. 28-31.

12. Choi JH, Park JM, Ahn SG. Comparative study of visual and instrumental analyses of shade selection. J Wuhan Univ Technol Mat Sci 2010;25:62.

13. van der Burgt TP, ten Bosch JJ, Borsboom PC, Kortsmit WJ. A comparison of new and conventional methods for quantification of tooth color. J Prosthet Dent 1990;63:155-62.

14. Bolt RA, Bosch JJ, Coops JC. Influence of window size in small-window colour measurement, particularly of teeth. Phys Med Biol 1994;39:1133-42.

15. http://documents.mx/documents/vita-easyshade-operating-manual. html. [Last accessed on 2017 Mar 02].

16. Paul SJ, Peter A, Rodoni L, Pietrobon N. Conventional visual vs. spectrophotometric shade taking for porcelain-fused-to-metal crowns: A clinical comparison. Int J Periodontics Restorative Dent 2004;24:222-31.

17. O'Brien WJ, Hemmendinger H, Boenke KM, Linger JB, Groh CL. Color distribution of three regions of extracted human teeth. Dent Mater 1997;13:179-85.

18. Zoric EK, Žagar M, Zlataric DK. Influence of gender on the patient's assessment of restorations on the upper anterior teeth. Acta Stomatol Croat 2014;48:33-41.

19. Sykora O. Fabrication of a posterior shade guide for removable partial dentures. J Prosthet Dent 1983;50:287-8.

20. O'Brien WJ, Oh WS, Piché PW. Color parameters of the chromascop shade guide. Dent J 2013;1:3-11.

21. Okubo SR, Kanawati A, Richards MW, Childress S. Evaluation of visual and instrument shade matching. J Prosthet Dent 1998;80:642-8.

22. Wee AG, Monaghan P, Johnston WM. Variation in color between intended matched shade and fabricated shade of dental porcelain. J Prosthet Dent 2002;87:657-66.

23. Chu SJ, Trushkowsky RD, Paravina RD. Dental color matching instruments and systems. Review of clinical and research aspects. J Dent 2010;38 Suppl 2:e2-16.

24. Elamin HO, Abubakr NH, Ibrahim YE. Identifying the tooth shade in group of patients using Vita Easyshade. Eur J Dent 2015;9:213-7. 